\title{
Integrating diet and exercise into care of prostate cancer patients on androgen deprivation therapy
}

This article was published in the following Dove Press journal:

Research and Reports in Urology

16 August 2016

Number of times this article has been viewed

\section{Mark A Moyad' \\ Robert U Newton ${ }^{2}$ \\ Ulf W Tunn ${ }^{3}$ \\ Damian Gruca ${ }^{4}$}

'Department of Urology, University of Michigan Medical Center, Ann Arbor, MI, USA; ${ }^{2}$ Exercise Medicine Research Institute, Edith Cowan University, Joondalup, WA, Australia; ${ }^{3}$ Urological Clinic, Facharztzentrum Academic Hospital Sana Klinikum Offenbach, Offenbach/Main, ${ }^{4} \mathrm{Global}$ Medical Affairs, AbbVie Deutschland, Ludwigshafen, Germany
Correspondence: Mark A Moyad Department of Urology, University of Michigan Medical Center, 1500 East Medical Center Drive, Ann Arbor, MI 48109-0330, USA

Tel +l 7349986078

Fax +I 7349369127

Email moyad@umich.edu
Abstract: Improved diagnosis and treatment regimens have resulted in greater longevity for men with prostate cancer. This has led to an increase in both androgen deprivation therapy (ADT) use and duration of exposure, and therefore to its associated adverse effects, such as sexual dysfunction, osteoporosis, reduced muscle mass, increased fat mass, and increased incidence of cardiovascular disease and type 2 diabetes. Given that the adverse effects of ADT are systemic, often debilitating, and difficult to treat, efforts continue in the development of new strategies for long-term management of prostate cancer. The PubMed database was searched to select trials, reviews, and meta-analyses in English using such search terms as "prostate cancer" and "androgen deprivation therapy", "cardiovascular risk", "lean body mass", "exercise", and "diet". The initial searches produced 379 articles with dates 2005 or more recent. Articles published after 2004 were favored. This review utilizes the latest data to provide a status update on the effects of exercise and diet on patients with prostate cancer, focusing on ADT-associated side effects, and it discusses the evidence for such interventions. Since the evidence of large-scale trials in patients with prostate cancer is missing, and an extrapolation of supporting data to all patient subgroups cannot be provided, individualized risk assessments remain necessary before the initiation of exercise and diet programs. Exercise, diet, and nutritional supplementation interventions have the potential to provide effective, accessible, and relatively inexpensive strategies for mitigating ADT-associated toxicities without introducing additional adverse effects. Keywords: androgen deprivation therapy, ADT, diet, exercise, nutrition, prostate cancer, dietary supplements

\section{Introduction}

Prostate cancer is the most frequently diagnosed cancer among men in developed countries. ${ }^{1}$ Widespread adoption of programs to screen for prostate-specific antigen has revolutionized the diagnosis and treatment of prostate cancer. Early detection and development of new treatment options have improved outcomes, increasing 5-year survival from $67.8 \%$ to $99.7 \%$ over the past 25 years, with 10 - and 15 -year survival presently at $99 \%$ and $94 \%$, respectively. ${ }^{2}$ Thus, prostate cancer has moved from an aggressive, often fatal, disease to a chronic condition requiring comprehensive management strategies to maintain patients' quality of life (QoL).

Androgen deprivation therapy (ADT) has long been the frontline treatment for advanced prostate cancer. ${ }^{3-8}$ Indeed, over a third of the roughly 3 million men in the USA presently diagnosed with prostate cancer have received or are receiving ADT. ${ }^{2}$ Although ADT has been found to improve the overall survival, it is also associated with 
adverse side effects, including sexual dysfunction, gynecomastia, hot flashes, osteoporosis, cognitive defects, reduced muscle mass, increased fat mass, and increased incidence of both cardiovascular disease and type 2 diabetes. ${ }^{9-12}$

Although earlier diagnosis and treatment have greatly extended patient longevity, they have also led to a considerably longer duration of ADT. An alternative, intermittent ADT has been proposed to mitigate the adverse effects of continuous ADT with the premise that it will not impact efficacy. ${ }^{13,14}$ Although intermittent ADT offers some relief from the side effects of continuous ADT, in particular during treatment pauses, comprehensive management plans aimed at helping patients cope with the long-term effects of ADT throughout all phases of therapy are essential, but are often missing.

Ninety percent of the patients with prostate cancer in the USA are aged 60 years or older, ${ }^{2}$ a population known to be at high risk for cardiovascular and diabetic comorbidities. ${ }^{15}$ Exercise and diet programs are important factors in reducing the risks of these conditions. ${ }^{16}$ Exercise and improved diet, therefore, have the potential to improve the QoL and also possibly the long-term survival of patients with prostate cancer (who may or may not be on ADT). ${ }^{17,18}$ Some clinical trial data, including that from multiple randomized controlled trials, have demonstrated the ability of exercise and dietary modifications to ameliorate ADT-associated adverse effects, and patients and physicians need to be informed about these nonpharmacologic approaches. Here, we review recent studies of exercise and nutritional interventions to assess their potential impact on the outcomes in patients with prostate cancer receiving ADT.

We searched the PubMed database to select trials, reviews, and meta-analyses in English in the last 10 years (2005-2015) using search terms "prostate cancer and cardiovascular diseases/diet/exercise/sexual dysfunction", "androgen deprivation therapy and diet/exercise/bone", and "cancer and body composition". The initial searches produced 3,863 records after the removal of duplicates. Figure 1 shows the flowchart of manuscript selection.

\section{Impact of exercise on patients with prostate cancer \\ Exercise, prostate cancer, and mortality risk}

The beneficial impact of regular physical activity on many chronic ailments, including cardiovascular disease, osteoporosis, diabetes, obesity, fatigue, and depression, has been reported in many studies, not least in the 1996 US Department of Health and Human Services Report of the Surgeon General. ${ }^{16}$ There is a paucity of good data with respect to the effect of exercise on the mortality of men with prostate cancer. Studies of cancer (including prostate cancer) have shown that there is a link between increased physical activity and improved physical functioning in cancer survivors. For example, the Reach out to Enhance Wellness study enrolled 641 elderly (mean age, 73 years), sedentary, overweight, or obese (mean body mass index [BMI], $29 \mathrm{~kg} / \mathrm{m}^{2}$ ) cancer survivors (including 94 prostate cancer survivors) and utilized a home-based diet and exercise intervention. The Reach out to Enhance Wellness intervention consisted of workbooks, equipment, and quarterly newsletters, endorsing $15 \mathrm{~min}$ utes of strength training every other day and 30 minutes of endurance exercise daily to evaluate the effects on physical function. The intervention produced a decrease in the rate of physical function decline, according to various self-reported measures, including the Medical Outcomes Study Short Form-36 (SF-36); the intervention also produced a decrease in BMI compared with the control (delayed intervention) population. ${ }^{19,20}$

Kenfield et $\mathrm{al}^{17}$ studied a population of 2,705 male health care professionals (mean age at prostate cancer diagnosis about 70 years) with nonmetastatic prostate cancer and found that those participating in vigorous physical activity (metabolic equivalent task $[\mathrm{MET}]$ value $^{21} \geq 6$ ) for a duration $\geq 3$ hours/week demonstrated a $49 \%$ lower risk of all-cause mortality and a $61 \%$ lower risk of death specifically from prostate cancer, compared with men who did $<1$ hour/week of vigorous activity. MET value is a way of defining the energy cost of physical activity in adults, and examples range from meditation (1 MET), stationary bike or jogging (7 METs), playing squash (12 METs), running up stairs (15 METs) to running at $14 \mathrm{mph}$ (25 METs). ${ }^{17}$ The men engaging in nonvigorous exercise (MET value $<6$, eg, walking at a normal to very brisk pace) $\geq 90$ minutes/week had an all-cause mortality risk $46 \%$ less than those who walked $<90$ minutes/week. There was, however, no statistically significant difference between nonvigorous exercise and walking with respect to prostate cancer-specific mortality. ${ }^{17}$ Other studies in large populations of men who were cancer-free at enrollment, however, have shown no significant association between physical activity, body weight, and waist girth and prostate cancer risk, ${ }^{22,23}$ although Patel et $\mathrm{al}^{23}$ suggest that physical activity may be associated with reduced risk of aggressive prostate cancer. ${ }^{23}$ 
Identification

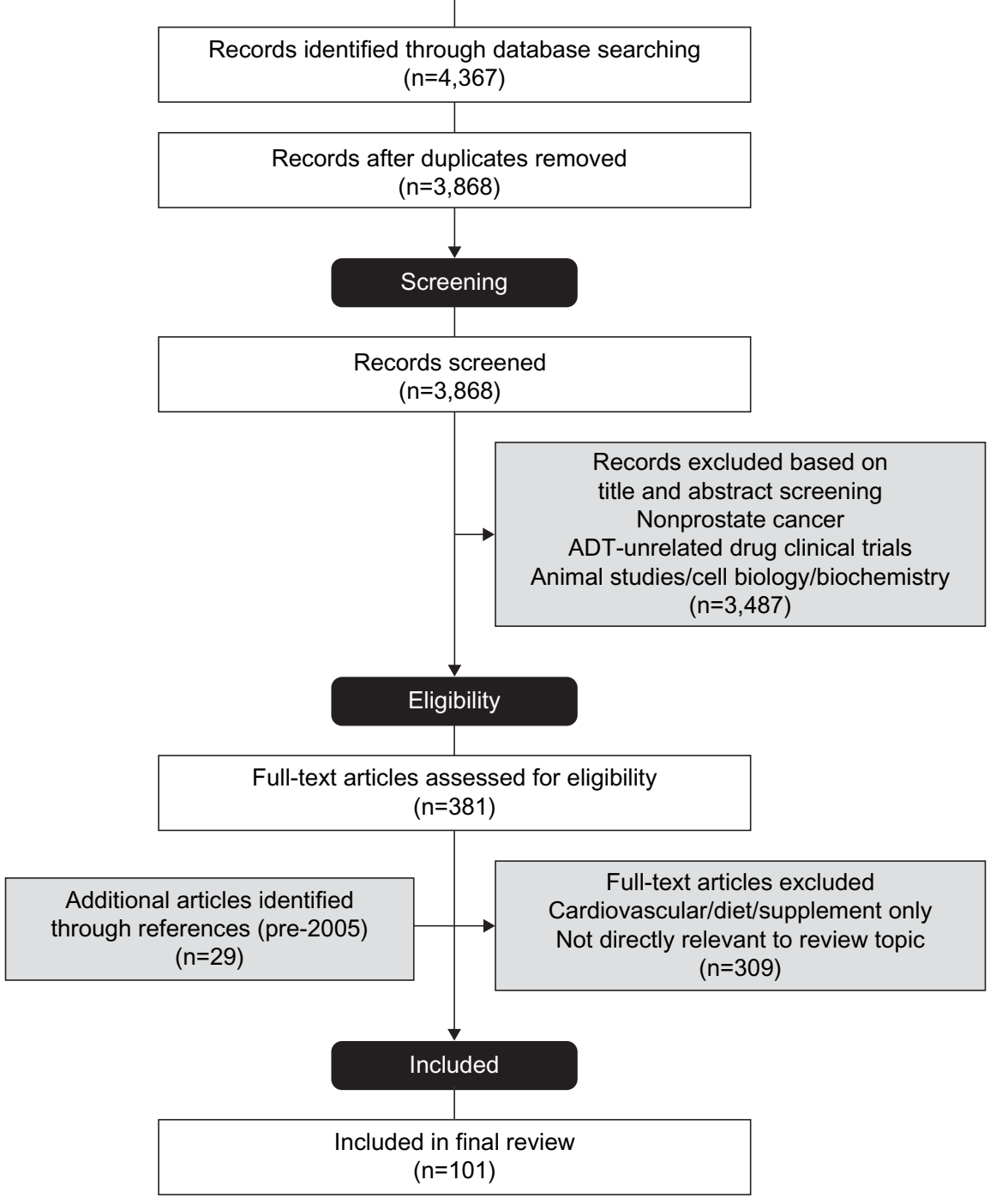

Figure I Flow diagram showing manuscript selection process.

Abbreviation: ADT, androgen deprivation therapy.

\section{Strength, lean body mass, and functional ability}

A systematic review of ten studies (five randomized and five uncontrolled clinical trials) examined the effects of exercise on patients receiving ADT. ${ }^{24}$ Study populations included both patients with metastatic and nonmetastatic prostate cancer, with mean ages ranging from 63 to 72 years, and with ADT duration of 4 to $>44$ months. The number of patients on ADT undergoing exercise interventions ranged from five in a pilot study ${ }^{25}$ to $74 .{ }^{26}$ Although most interventions included two to six exercise-based sessions per week for 24 weeks, the interventions were heterogeneous, varying in duration, frequency, intensity, and degree of supervision. Despite this heterogeneity, the evidence demonstrated that physical performance was improved by exercise. Randomized controlled trials found exercise to be consistently beneficial for muscular performance: reported as increases in muscular strength and increases in upper and lower limb strength, compared with the control population (see, eg, Bourke et $\mathrm{al}^{27}$ and Galvão et $\mathrm{al}^{28}$ ). Although one study found improvement in cardiovascular fitness ${ }^{27}$ and others showed improvements in $400-\mathrm{m}^{29}$ or 6 -minute walk times, ${ }^{25}$ still other studies showed no improvement in 6-minute walk times or in cardiorespiratory fitness. ${ }^{30,31}$

Body composition is a component of many studies investigating exercise effects on prostate cancer patients on ADT, ${ }^{24}$ and resistance training has been shown to either increase lean body mass ${ }^{28}$ or reduce its decline ${ }^{26}$ in randomized controlled trials. Other uncontrolled studies have shown increased lean body mass, ${ }^{29}$ decreased BMI, or decreased weight with resistance exercise. ${ }^{29,32}$ The data on adiposity are not clear, 
as some studies report an adiposity reduction, ${ }^{30,33}$ whereas others report no differences between exercising and control groups. ${ }^{26-28}$

\section{Fatigue}

Fatigue measurements, assessed by patient-reported questionnaires, such as the Functional Assessment of Cancer Therapy-Fatigue (FACT-F) ${ }^{34}$ or the Functional Assessment of Chronic Illness Therapy-Fatigue, ${ }^{35}$ are frequently assessed together with exercise outcomes in these studies. ${ }^{24,36,37}$ In general, the evidence is equivocal as to whether exercise helps diminish patient-reported fatigue. Some studies show clinically meaningful improvement versus controls, ${ }^{26,27,33,38}$ whereas another failed to show benefit. ${ }^{30}$ Some uncontrolled studies show benefit; for example, Hanson et $\mathrm{al}^{29}$ showed that in 17 black men on ADT, strength training reduced fatigue perception by $38 \%$, which exceeds changes reported in other cancer survivor studies. On the other hand, for example, Hansen et $\mathrm{al}^{25}$ found that exercise training in ten men with prostate cancer produced no significant difference in fatigue between those on ADT and those who were not. Neither of these studies was large enough to allow statistically meaningfully comparisons to be made between the groups.

\section{QoL}

Many controlled and uncontrolled studies report that physical activity improves aspects of patient-reported QoL. The most widely used measures for self-reported general and psychosocial QoL (mental health/emotional well-being) are the Medical Outcomes Study 12-item Short Form (SF-12) and the SF-36. ${ }^{24,39}$ A 3-month exercise program consisting of aerobic and resistance exercises produced clinically significant improvement in the SF-36 scores of 32 men with prostate cancer starting ADT, compared with 31 men starting ADT on usual care but not exercising. ${ }^{38}$ Likewise, in a pilot study, resistance exercise training sessions three times a week for 12 weeks produced clinically significant prostate cancer-specific improvement in the QoL for five men on ADT, compared with those on usual care, as measured by the FACT-Prostate scale. ${ }^{25}$ In contrast, however, Cormie et $\mathrm{l}^{36}$ studied 20 men with bone metastases secondary to prostate cancer and found no significant between-group differences in QoL or psychological distress comparing those who underwent a 12 -week resistance exercise program and those on usual care.

Interestingly, a study of 66 prostate cancer survivors compared home-based aerobic training with home-based resistance training and found that after 6 months, the aerobic group had undertaken significantly more physical activity than the resistance training group, although fatigue and $\mathrm{QoL}$ were not significantly different between the two groups. ${ }^{31}$ This suggests that aerobic exercise may be more attractive to the prostate cancer population than resistance exercises. This has implications as aerobic exercise is anticipated to have a greater impact on cardiovascular health, whereas resistance exercise is more associated with increases in muscular strength and lean body mass.

\section{Cardiovascular disease}

In 2006, the Surveillance, Epidemiology, and End Results Medicare study reported an observed $11 \%$ increase in myocardial infarction risk and a $16 \%$ increased risk of coronary heart disease and death from cardiac arrest in an observational study of prostate cancer patients receiving ADT, versus those not on hormone therapy $(n=73,196){ }^{3}$ In a later study of men in the Veterans Healthcare Administration database, ADT was also found to be associated with stroke. ${ }^{40}$ These reports, along with observational evidence from several additional studies linking ADT to an increased risk of cardiovascular events, prompted the US Food and Drug Administration to issue a communication in 2010 requiring that manufacturers of drugs for ADT include a warning label citing an increased risk of diabetes and certain cardiovascular diseases (eg, heart attack, sudden cardiac death, and stroke) with their use. ${ }^{41}$ The link between ADT and cardiovascular events remains somewhat controversial; however, as subsequent studies indicate that although ADT appears to be linked to an increased risk for cardiovascular events, it is not associated with higher rates of related mortality. ${ }^{11,42}$

Although there are no studies to date that are specifically powered to evaluate the effect of exercise on ADT-mediated cardiovascular events, there is a large body of evidence supporting the role of physical activity in the prevention and management of cardiovascular disease in broader populations. ${ }^{43-46}$ Many plausible mechanisms could be involved in the protective effects of physical activity, including protection against atherosclerosis, improvement of plasma lipid and lipoprotein profile, dilation of peripheral blood vessels/ attenuation of sympathetic nervous activity leading to reduction in blood pressure, adaptations to coronary circulation, reduction in thromboses due to enhanced fibrinolysis, and decrease in the aggregation and adhesion of platelets. ${ }^{16,47,48} \mathrm{By}$ extension, it seems likely that implementation of an exercise program would help mitigate the cardiovascular risk factors associated with ADT, although further research is necessary. 


\section{Bone health}

Bone density reduction is a serious consequence of ADT, with the frequency of osteoporosis and osteopenia being directly proportional to treatment duration. ${ }^{49-51}$ This is particularly significant in men, as a high mortality rate (up to $37.5 \%$ ) is associated with minimal trauma fractures. ${ }^{52}$ The greatest loss of bone mineral density occurs in the first year of ADT, with noticeable changes seen within months as androgen levels decline ${ }^{53}$ Many epidemiologic studies have reported that low body weight and low BMI are risk factors for diminished bone mineral density and fragility fracture. An explanation for the correlation of higher body weight and bone resilience is that this may be due to increased mechanical load on the bones in heavier persons stimulating an increase in bone mineral density. ${ }^{54,55}$ There is considerable evidence that physical activities involving mechanical loading, such as resistance training and high-impact load-bearing exercises, are beneficial for bone health in the general population. ${ }^{16,52}$ In contrast to this view, however, a recent study of a heterogeneous cohort of 8,833 men aged 18-64.9 years used computed tomography to show an inverse relationship between adiposity (BMI and visceral and subcutaneous adiposity) and bone quality. ${ }^{56}$

Despite the known effects of ADT on bone health, there is a paucity of data available regarding the impact of exercise on the bone health of patients receiving ADT. Recently, a randomized controlled study in 63 men with prostate cancer examined the effect of moderate- to high-intensity aerobic and resistance exercises in preventing ADT-associated toxicity in the first 3 months of treatment and found no significant difference in bone mineral density loss and in blood biomarkers of bone turnover between the exercise and usual care groups ${ }^{38}$ The authors speculated that the efficacy of exercise-based interventions will likely require incorporation of targeted, high-impact activities that provide skeletal loading, such as jumping and hopping. Indeed, similar results have been observed in resistance training studies in older men and women, where only high-intensity, and not moderate-intensity, strength training resulted in increased bone mineral density. ${ }^{57-59}$

A clinically important issue is whether high-impact or moderate- to high-intensity exercise might put patients with prostate cancer at risk of fracture, particularly in $70 \%-80 \%$ of advanced prostate cancer patients who have bone metastases. ${ }^{60}$ The risk increases further given the effect that ADT has on bone health. For example, a study of 19,079 Canadian men with prostate cancer demonstrated a $65 \%$ increased fragility risk for those on at least 6 months of ADT, compared with those not on ADT. ${ }^{61}$ Exercise, therefore, is commonly not recommended for this population, due to fears over fragility and potential fracture. However, a recent randomized, preliminary, 12-week study of targeted, moderate- to highintensity exercise in 20 prostate cancer patients with bone metastases, found that the exercise was well tolerated, with 93\% patient compliance and no reported adverse events. ${ }^{36}$ This provides initial evidence that supervised resistance exercise may be safe for prostate cancer patients with metastatic bone disease, although the data from this trial showed that the intervention made no significant changes to the patients' bone mineral density. The supervised exercise did, however, improve other measures, such as physical activity, muscular strength, and lean body weight. More studies involving larger numbers of subjects are required to build on these results.

\section{Sexual dysfunction}

About $30 \%-90 \%$ of prostate cancer patients have been reported to experience adverse sexual side effects from their care treatments. ${ }^{62-64}$ Sexual dysfunction can profoundly affect patients' QoL and lead to depression, loss of connection with their partner, and decline in their identity as a man. ${ }^{62,64}$ Addressing ADT complications will likely play an important role in improving the overall outcomes.

Kratzik et al ${ }^{65}$ observed that in healthy men aged $45-60$ years $(n=674)$, risk of severe erectile dysfunction was $83 \%$ less among men who exercised $\geq 3,000 \mathrm{kcal} /$ week, compared with those who exercised $\leq 3,000 \mathrm{kcal} /$ week. In two studies, Cormie et al ${ }^{38,66}$ examined the effect of moderate- to high-intensity exercise (resistance and aerobic) over a 12-week intervention. Using the sexual function section of the European Organization for Research and Treatment of Cancer prostate cancer-specific module questionnaire, the researchers found significant differences between the usual care (nonexercise) group and the exercise group, with the latter reporting maintenance of sexual activity and a higher percentage of participants with a major interest in sex $(17.2 \%$ vs $0 \%, P=0.024){ }^{38,66}$ In-depth interviews with 18 men (mean age, 63.1 years) receiving ADT for prostate cancer suggest that exercise may be helpful in alleviating sexual dysfunction in a broader, less specific manner. The role of exercise in mitigating the reduction in lean body mass and muscular strength seen with ADT may be important in improving the subjects' perceptions of their masculinity, which in turn leads to a better psychological frame of mind with respect to their sexuality. ${ }^{67}$ Further research is needed, but this preliminary data suggest that exercise may be able to play a role in reducing ADT-associated sexual dysfunction. 


\section{Metabolic syndrome}

ADT is associated with significant adverse metabolic effects, including elevated serum triglycerides $(\geq 150 \mathrm{mg} / \mathrm{dL})$; fasting serum glucose $\geq 100 \mathrm{mg} / \mathrm{dL}$; weight gain, especially of the abdomen; peripheral insulin resistance; and increased diabetes risk. ${ }^{3,9,40,68}$ These effects are characteristics of metabolic syndrome and increase the risk of heart disease and stroke, in addition to diabetes. ${ }^{69}$

We reviewed the data on cardiovascular fitness earlier, and there is good evidence that exercise improves or mitigates the decline in lean body mass and decreases the BMI of patients on ADT. There is also the additional evidence that exercise may impact the overall all-cause mortality, of which cardiovascular events are a large proportion. Exercise that is considered desirable in a noncancer population is also likely to show benefit in men with prostate cancer. Segal et $\mathrm{al}^{26}$ reported that 12 weeks of resistance training in 155 men with prostate cancer and receiving ADT resulted in significantly greater upper and lower body muscular fitness, compared with those on usual (nonexercise) care; however, waist circumference, BMI, or subcutaneous adiposity differences between groups were not significant.

Recently, two studies ${ }^{38,70}$ have shown that exercise-based interventions are promising methods for reducing few ADTspecific metabolic effects. Results from a randomized pilot study assessed the impact of over 6 months of combined metformin, a low-glycemic-index diet, and exercise in 20 prostate cancer patients at ADT initiation and compared this with 20 men who were on ADT alone. The metformin and exercise group had decreased abdominal girth, weight, BMI, and systolic blood pressure, compared with the group on ADT treatment alone, although insulin-resistant biochemical markers were not significantly different. In this small study, however, it was not possible to separate the metformin and dietary effects from the exercise components. ${ }^{70}$ In the study by Cormie et $\mathrm{al}^{38}, 63$ prostate cancer patients were randomized to receive either a 3-month aerobic and resistance exercise program or usual care, concomitant to initiation of ADT. Patients receiving the exercise-based intervention demonstrated significant reductions in ADT-associated metabolic effects, including decreased whole body fat mass, trunk fat mass, and percentage fat, compared with the usual care control group. The ratio of total cholesterol to high-density lipoprotein (HDL) cholesterol improved in the exercise group, which is clinically significant, as this ratio is a common cardiovascular disease risk marker. There were no significant changes, however, in other cardiovascular and metabolic biomarkers, such as triglycerides, insulin and glucose levels, or glycated hemoglobin. ${ }^{38}$
Evidence from trials has also shown that ADT can cause significant increases in HDL. ${ }^{38,71-73} \mathrm{~A}$ feature of ADT-associated metabolic changes is that HDL is usually elevated, which is not typical with metabolic syndrome (where HDL levels are low).$^{72,73}$ Potentially, HDL increases could be further amplified by the addition of prescriptive exercise. Although these are preliminary studies, they suggest that exercise may provide some benefit in lessening the adverse metabolic effects of ADT. Two randomized trials are presently being conducted to investigate this further. ${ }^{74,75}$

C-reactive protein, an inflammation marker commonly elevated in metabolic syndrome, showed a clinically meaningful reduction in a randomized controlled trial of exercise in 57 men on $\mathrm{ADT} .^{28}$ Going forward, further study is required to investigate the correlations between $\mathrm{C}$-reactive protein level and exercise.

Although the final verdict from large-scale trials is still outstanding, exercise programs should be considered an integral part of treatment for men with prostate cancer, as they can provide low-cost, scalable, and widely accessible strategies to help counter the systemic effects associated with prostate cancer therapies, including ADT. Exercise impacts patient well-being, both physical and psychological, potentially leading to improved physical functioning and survival. ${ }^{24,39,75-77}$ However, before a general recommendation can be issued, treating physicians should exercise caution when considering to institute exercise and diet programs, and patients should be carefully assessed prior to any intervention.

\section{Effect of nutrition and dietary supplements on the complications of ADT}

\section{Nutrition and dietary supplements}

There is a lack of data on how nutritional adjustments might affect ADT-associated adverse effects and the few studies that have investigated the integration of either nutritional counseling or modified diet have done so in conjunction with another intervention, making it difficult to specifically assess the impact of dietary changes. ${ }^{70,78}$ Given the similarities to what is observed in postmenopausal women, however, some researchers have made specific recommendations for lifestyle modifications, including smoking cessation, moderation of alcohol and caffeine intake, and supplementation with vitamin $\mathrm{D}$ and calcium. ${ }^{79,80}$ As mentioned in the previous section, a low-glycemic-index diet, regular exercise, and metformin treatment have been shown to significantly improve abdominal girth, weight, BMI, and systolic blood pressure in patients receiving $\mathrm{ADT} .{ }^{70} \mathrm{Caffeine}$ is also garnering research as a method to potentially improve workout energy levels and 
duration and postworkout discomfort. ${ }^{81}$ Studies with prostate cancer patients are lacking, although caffeine consumed $(0.16 \mathrm{mg} / \mathrm{kg}$ anhydrous caffeine $) 1$ hour before completing a number of functional performance and exercise capacity tests has been reported to increase the exercise capacity by $3.0 \%$ versus placebo in a randomized, double-blind crossover study in 30 prostate cancer survivors. There was no significant difference, however, in postexercise fatigue and perception of exertion compared with placebo, nor in other functional performance measures. ${ }^{82}$

\section{Bone health}

Despite the debilitating effects of osteoporosis observed in men receiving ADT, few studies have examined two key modulators of bone health in this population: vitamin $\mathrm{D}$ and calcium. Bone density deterioration is known to occur shortly after initiation of ADT. ${ }^{49,50}$ A meta-analysis of calcium and vitamin $D$ studies in women and men aged $\geq 50$ years $(92 \%$ of study participants were women and those with secondary osteoporosis were excluded) provided evidence that calcium and vitamin D supplementation is associated with a reduced rate of bone mineral density loss in the hip and the spine, and also with decreased risk of fracture. ${ }^{83}$ On the basis of this evidence, the European Association of Urology has recommended that calcium and vitamin D supplements be monitored both prior to and during ADT if serum concentrations fall below the lower limit of normal (normal range: calcium, $2.2-2.6 \mathrm{nmol} / \mathrm{L}$; vitamin $\mathrm{D}, 100-160 \mathrm{nmol} / \mathrm{L}){ }^{84}$ In its most recent guidelines, the European Association of Urology recommends that a daily intake of $\geq 1,200 \mathrm{mg} /$ day of calcium and 1,000 IU of vitamin D may be useful for improving bone mineralization in prostate cancer patients. ${ }^{84}$ The National Osteoporosis Foundation, on the other hand, supports the Institute of Medicine guidelines recommending that men aged 50-70 years consume 1,000 mg/day of calcium, and those $\geq 71$ years, $1,200 \mathrm{mg} /$ day of calcium. ${ }^{85,86}$

A systematic review of twelve clinical trials, however, failed to find conclusive support for these recommendations in prostate cancer patients receiving ADT, noting that the frequently recommended daily doses of calcium (500-1,000 $\mathrm{mg}$ ) and vitamin D (200-500 IU) were insufficient to prevent ADT-associated bone density loss. ${ }^{87}$ More recently, in a prospective longitudinal study, Alibhai et al ${ }^{88}$ examined the long-term effects of calcium and vitamin $\mathrm{D}$ supplementation in 160 prostate cancer patients (mean age, 69 years), with and without ADT. Vitamin D, but not calcium, was shown to provide some protection from bone density loss, especially in the first year of ADT. It seems likely that the efficacy of vitamin $\mathrm{D}$ and calcium supplementation may require implementation of concomitant exercise programs to stimulate bone accrual, as discussed earlier. ${ }^{36,38,75}$

\section{Fat and muscle mass}

Although there are a number of randomized controlled trials that have demonstrated exercise to be effective for reducing fat mass in overweight older men, ${ }^{89}$ the absence of testosterone in men on ADT has proven to be a more difficult challenge. It has been reported that during the early phase of ADT, fat loss or maintenance of BMI can be achieved through exercise alone. ${ }^{38,90}$ This concept remains controversial, however, as other studies have suggested that, in addition to exercise, caloric restriction is required for consistent fat loss in men. ${ }^{89,91}$

Loss of muscle mass, which has major consequences for physical function and risk of metabolic disease, is a frequently reported adverse effect of ADT. ${ }^{11}$ Resistance training has consistently been associated with muscle hypertrophy in men on ADT. ${ }^{28,31}$ This effect is likely to be amplified by appropriate nutritional supplementation, including protein, carbohydrates, and creatine monohydrate, as has been demonstrated in studies of both younger and older men not on ADT. ${ }^{92}$ Recently, a meta-analysis of 14 randomized controlled trials in a total of 626 adults showed an increase in weight loss, lean body mass, and a decrease in visceral fat among men receiving supplemental whey protein in combination with resistance training. ${ }^{93}$ Although more studies are needed, the potential for whey protein or another similar protein isolate to mitigate the adverse effects of prostate cancer therapies is considerable.

\section{Fatigue}

Encouraging data from a randomized, double-blind, phase III trial of American ginseng (2,000 mg/day) found a statistically significant and clinically meaningful decrease in cancer-related fatigue in 171 patients (4\% of whom had prostate cancer), compared with 170 patients on placebo. ${ }^{94}$ The primary endpoint was the Multidimensional Fatigue Symptom Inventory-Short Form. American ginseng is the first treatment option, besides exercise, to show efficacy in addressing cancer-related fatigue, as no other drugs, including stimulants, have been proven to be effective. Interestingly, similar to what was observed with exercise, ${ }^{38}$ greater benefits were found in patients who started ginseng at the same time as their cancer treatment, compared with patients who started ginseng after treatment initiation. This suggests that treatment with American ginseng should be started at the same time or prior to ADT initiation; however, this needs to be confirmed with a larger study population of patients with prostate cancer. 


\section{Cardiovascular disease}

The impact of ADT on cardiovascular disease development and progression remains contested in the literature. Regardless, heart disease is a leading cause of mortality in all men, including those on ADT. ${ }^{42}$ Lifestyle changes, such as modifications to diet and exercise, may significantly affect cardiovascular disease risk in prostate cancer patients on ADT. ${ }^{18}$

Although it has not been studied in patients on ADT, fish oil has been approved by the Food and Drug Administration for use in lowering triglycerides. ${ }^{95}$ Correspondingly, the American Heart Association recommends that individuals with heart disease take 1,000 $\mathrm{mg}$ of eicosapentaenoic acid (EPA) and docosahexaenoic acid (DHA), the primary omega-3 fatty acid components of fish oil, daily. ${ }^{96}$ Indeed, a large, randomized controlled trial (Japan EPA Lipid Intervention Study) in 18,645 Japanese subjects has shown synergistic effects between omega-3 acids and statins in reducing serum triglycerides in patients with high cholesterol. ${ }^{97,98}$ Interestingly, further subgroup analysis found that fish oil significantly reduced the incidence of coronary artery disease in subjects with impaired glucose metabolism $(-22 \%)$, even greater than that observed for subjects with normal glucose metabolism $(-18 \%){ }^{97}$

\section{Conclusions}

The advent of prostate-specific antigen screening programs, greater public awareness of prostate cancer, and improved treatment regimens have fundamentally altered the disease landscape. A consequence of greater patient longevity is a more extended exposure to ADT and its associated adverse effects. Given that the adverse effects of ADT are systemic, often debilitating, and difficult to treat, efforts are being made in the development of new strategies for long-term management of prostate cancer.

As summarized in Table 1, exercise, diet, and nutritional supplementation interventions have the potential to provide

Table I Adverse effects reported with ADT and potential lifestyle, supplemental, and prescription medication solutions

\begin{tabular}{|c|c|c|c|}
\hline \multirow{2}{*}{$\begin{array}{l}\text { ADT-associated } \\
\text { adverse effects }\end{array}$} & \multirow[b]{2}{*}{ Exercise } & \multicolumn{2}{|l|}{ Potential solutions } \\
\hline & & Diet & Drugs \\
\hline Anemia & \multicolumn{3}{|c|}{$\begin{array}{l}\text { - Primarily normochromic, normocytic anemia with ADT, thus no lifestyle or supplemental options available for } \\
\text { treatment }{ }^{99} \\
\text { - Asymptomatic in } 90 \% \text { of patients, so medication is rarely, if ever, needed }{ }^{99}\end{array}$} \\
\hline Bone loss & \multicolumn{2}{|c|}{$\begin{array}{l}\text { Resistance exercise } 2-3 \text { times a week in combination with I,000-I,200 } \\
\mathrm{mg} \text { of calcium and } 800-1,000 \mathrm{IU} \text { of vitamin D (from food and/or } \\
\text { supplements) } 36,51,100\end{array}$} & $\begin{array}{l}\text { - Prescription medication should be } \\
\text { considered based on the duration of ADT } \\
\text { and documented severity of bone loss }\end{array}$ \\
\hline Fatigue & Resistance exercise ${ }^{24,38}$ & $\begin{array}{l}\text { - Caffeine from beverages } \\
\text { (general stimulant })^{81} \\
\text { - American ginseng }(2,000 \mathrm{mg} / \\
\text { day at } 3 \%-5 \% \text { ginsenosides })^{94}\end{array}$ & \\
\hline Hot flashes & $\begin{array}{l}\text { Maintaining a healthy weight may } \\
\text { reduce the severity of vasomotor } \\
\text { symptoms and moderate aerobic } \\
\text { exercise could also be beneficial }\end{array}$ & $\begin{array}{l}\text { No dietary supplement has } \\
\text { demonstrated a consistent } \\
\text { benefit over placebo }{ }^{101}\end{array}$ & $\begin{array}{l}\text { - Prescription medication can be effective } \\
\text { (eg, megestrol acetate, venlafaxine) for } \\
\text { moderate-to-severe QoL - altering hot } \\
\text { flashes }^{101}\end{array}$ \\
\hline $\begin{array}{l}\text { Lipids and/or prediabetes } \\
\text { (elevated cardiovascular } \\
\text { risk) }\end{array}$ & $\begin{array}{l}\text { - ADT has controversial } \\
\text { cardiovascular risk data }{ }^{18} \\
\text { - Diet and exercise } e^{80} \\
\text { - Abnormal glucose levels may } \\
\text { respond to diet and exercise }{ }^{70}\end{array}$ & $\begin{array}{l}\text { Omega-3 fatty acids (EPA/DHA; } \\
500 \mathrm{mg} / \mathrm{dL} \text { or more) FDA- } \\
\text { approved for hypertriglyceridemia } \\
\text { only (although studies lack clinical } \\
\text { endpoints) }\end{array}$ & $\begin{array}{l}\text { - When appropriate, low-dose statin and/or } \\
\text { ezetimibe prescription treatment; low-dose } \\
\text { aspirin for those who qualify, based on } \\
\text { overall cardiovascular risk } \\
\text { - When appropriate, prescription metformin } \\
\text { has preliminary data with ADT }{ }^{70}\end{array}$ \\
\hline Sarcopenia & $\begin{array}{l}\text { Resistance exercise } 2-3 \text { times per } \\
\text { vitamin D recommended daily inta }\end{array}$ & $\begin{array}{l}\text { in addition to calcium and } \\
\text { as for bone loss) } \text { ) }^{28,92} \\
\text { - Preliminary indirect evidence } \\
\text { suggests that whey protein } \\
\text { isolate (or another protein } \\
\text { isolate) at } 20-25 \text { g per day } \\
\text { could also assist with muscle } \\
\text { protein synthesis }{ }^{93}\end{array}$ & \\
\hline $\begin{array}{l}\text { Weight gain (visceral } \\
\text { adipose tissue } \\
\text { accumulation) }\end{array}$ & $\begin{array}{l}\text { Diet and aerobic and resistance } \\
\text { exercise }^{24,38}\end{array}$ & $\begin{array}{l}\text { Whey protein isolate may also } \\
\text { assist with appetite suppression }\end{array}$ & $\begin{array}{l}\text { - Metformin ( } 850 \mathrm{mg} \text { twice a day) has } \\
\text { preliminary data for weight loss with } \mathrm{ADT}^{70}\end{array}$ \\
\hline
\end{tabular}

Notes: Not all the adverse events listed in this table are discussed in this review. We refer the reader to the scientific literature for more detailed discussions of these. Abbreviations: ADT, androgen deprivation therapy; DHA, docosahexaenoic acid; EPA, eicosapentaenoic acid; FDA, US Food and Drug Administration; IU, international unit; QoL, quality of life. 
relatively inexpensive and accessible strategies for mitigating many ADT-associated toxicities and are unlikely to introduce additional adverse effects. However, since the evidence of large-scale trials in patients with prostate cancer is missing, and an extrapolation of supporting data to all patient subgroups cannot be provided, individualized risk assessments remain necessary before the initiation of exercise and diet programs. The coordinated efforts of health care professionals, including exercise physiologists and dieticians, coupled with increased patient awareness, will be critical for effective implementation of such intervention programs, and future research would help to further our understanding of the effectiveness of diet and exercise in this complex patient population.

\section{Acknowledgments}

Medical writing and editorial support was provided by Audrey Vandervelde, PhD, and Robin Smith, PhD, of The Curry Rockefeller Group, LLC, Tarrytown, NY. Funding for this support was provided by AbbVie.

\section{Disclosure}

Mark Moyad has served as a consultant and on the speaker's bureau for AbbVie; has served as a consultant for Farr Labs, and is an author of the Promoting Wellness Series of Books. Robert Newton and Ulf Tunn report no conflicts of interest in this work. Damian Gruca is an employee of and owns stock in AbbVie.

\section{References}

1. Torre LA, Bray F, Siegel RL, Ferlay J, Lortet-Tieulent J, Jemal A. Global cancer statistics, 2012. CA Cancer J Clin. 2015;65(2): 87-108.

2. DeSantis CE, Lin CC, Mariotto AB, et al. Cancer treatment and survivorship statistics, 2014. CA Cancer J Clin. 2014;64(4):252-271.

3. Keating NL, O'Malley AJ, Smith MR. Diabetes and cardiovascular disease during androgen deprivation therapy for prostate cancer. J Clin Oncol. 2006;24(27):4448-4456.

4. Lu-Yao GL, Albertsen PC, Moore DF, et al. Survival following primary androgen deprivation therapy among men with localized prostate cancer. JAMA. 2008;300(2):173-181.

5. Mottet N, Bellmunt J, Bolla M, et al. EAU guidelines on prostate cancer. Part II: treatment of advanced, relapsing, and castration-resistant prostate cancer. Eur Urol. 2011;59(4):572-583.

6. Perlmutter MA, Lepor H. Androgen deprivation therapy in the treatment of advanced prostate cancer. Rev Urol. 2007;9(Suppl 1):S3-S8.

7. Sharifi N, Gulley JL, Dahut WL. Androgen deprivation therapy for prostate cancer. JAMA. 2005;294(2):238-244.

8. Sharifi N, Gulley JL, Dahut WL. An update on androgen deprivation therapy for prostate cancer. Endocr Relat Cancer. 2010;17(4):R305-R315.

9. Ahmadi H, Daneshmand S. Androgen deprivation therapy: evidencebased management of side effects. BJU Int. 2013;111(4):543-548.

10. Cheung AS, Zajac JD, Grossmann M. Muscle and bone effects of androgen deprivation therapy: current and emerging therapies. Endocr Relat Cancer. 2014;21(5):R371-R394.
11. Nguyen PL, Alibhai SM, Basaria S, et al. Adverse effects of androgen deprivation therapy and strategies to mitigate them. Eur Urol. 2015; 67(5):825-836.

12. Van Poppel H, Tombal B. Cardiovascular risk during hormonal treatment in patients with prostate cancer. Cancer Manag Res. 2011; 3:49-55.

13. Tunn U. The current status of intermittent androgen deprivation (IAD) therapy for prostate cancer: putting IAD under the spotlight. BJU Int. 2007;99(Suppl 1):19-22; discussion 23-14.

14. Gruca D, Bacher P, Tunn U. Safety and tolerability of intermittent androgen deprivation therapy: a literature review. Int J Urol. 2012; 19(7):614-625.

15. Grundy SM, Benjamin IJ, Burke GL, et al. Diabetes and cardiovascular disease: a statement for healthcare professionals from the American Heart Association. Circulation. 1999;100(10):1134-1146.

16. Centers for Disease Control and Prevention. A Report of the Surgeon General: Physical Activity and Health. 1996. Atlanta (GA): US Department of Health and Human Services. Available from: www.cdc.gov/ nccdphp/sgr/pdf/sgrfull.pdf. Accessed March 3, 2016.

17. Kenfield SA, Stampfer MJ, Giovannucci E, Chan JM. Physical activity and survival after prostate cancer diagnosis in the health professionals follow-up study. J Clin Oncol. 2011;29(6):726-732.

18. Moyad MA, Roach M 3rd. Promoting wellness for patients on androgen deprivation therapy: why using numerous drugs for drug side effects should not be first-line treatment. Urol Clin North Am. 2011;38(3):303-312.

19. Demark-Wahnefried W, Morey MC, Sloane R, et al. Reach out to enhance wellness home-based diet-exercise intervention promotes reproducible and sustainable long-term improvements in health behaviors, body weight, and physical functioning in older, overweight/obese cancer survivors. J Clin Oncol. 2012;30(19):2354-2361.

20. Morey MC, Snyder DC, Sloane R, et al. Effects of home-based diet and exercise on functional outcomes among older, overweight longterm cancer survivors: RENEW: a randomized controlled trial. JAMA. 2009;301(18):1883-1891.

21. Ainsworth BE, Haskell WL, Herrmann SD, et al. 2011 Compendium of Physical Activities: a second update of codes and MET values. Med Sci Sports Exerc. 2011;43(8):1575-1581.

22. Lee IM, Sesso HD, Paffenbarger RS, Jr. A prospective cohort study of physical activity and body size in relation to prostate cancer risk (United States). Cancer Courses Control. 2001;12(2):187-193.

23. Patel AV, Rodriguez C, Jacobs EJ, Solomon L, Thun MJ, Calle EE. Recreational physical activity and risk of prostate cancer in a large cohort of U.S. men. Cancer Epidemiol Biomark Prev. 2005;14(1):275-279.

24. Gardner JR, Livingston PM, Fraser SF. Effects of exercise on treatmentrelated adverse effects for patients with prostate cancer receiving androgen-deprivation therapy: a systematic review. J Clin Oncol. 2014;32(4):335-346.

25. Hansen PA, Dechet CB, Porucznik CA, LaStayo PC. Comparing eccentric resistance exercise in prostate cancer survivors on and off hormone therapy: a pilot study. PM R. 2009;1(11):1019-1024.

26. Segal RJ, Reid RD, Courneya KS, et al. Resistance exercise in men receiving androgen deprivation therapy for prostate cancer. $J$ Clin Oncol. 2003;21(9):1653-1659.

27. Bourke L, Doll H, Crank H, Daley A, Rosario D, Saxton JM. Lifestyle intervention in men with advanced prostate cancer receiving androgen suppression therapy: a feasibility study. Cancer Epidemiol Biomark Prev. 2011;20(4):647-657.

28. Galvão DA, Taaffe DR, Spry N, Joseph D, Newton RU. Combined resistance and aerobic exercise program reverses muscle loss in men undergoing androgen suppression therapy for prostate cancer without bone metastases: a randomized controlled trial. J Clin Oncol. 2010;28(2):340-347.

29. Hanson ED, Sheaff AK, Sood S, et al. Strength training induces muscle hypertrophy and functional gains in black prostate cancer patients despite androgen deprivation therapy. J Gerontol A Biol Sci Med Sci. 2013;68(4):490-498. 
30. Culos-Reed SN, Robinson JW, Lau H, et al. Physical activity for men receiving androgen deprivation therapy for prostate cancer: benefits from a 16-week intervention. Support Care Cancer. 2010;18(5): 591-599.

31. Santa Mina D, Alibhai SM, Matthew AG, et al. A randomized trial of aerobic versus resistance exercise in prostate cancer survivors. JAging Phys Act. 2013;21(4):455-478.

32. Culos-Reed SN, Robinson JL, Lau H, O'Connor K, Keats MR. Benefits of a physical activity intervention for men with prostate cancer. $J$ Sport Exerc Psychol. 2007;29(1):118-127.

33. Segal RJ, Reid RD, Courneya KS, et al. Randomized controlled trial of resistance or aerobic exercise in men receiving radiation therapy for prostate cancer. J Clin Oncol. 2009;27(3):344-351.

34. Cella D. The Functional Assessment of Cancer Therapy-Anemia (FACT-An) Scale: a new tool for the assessment of outcomes in cancer anemia and fatigue. Semin Hematol. 1997;34(3 Suppl 2):13-19.

35. Yellen SB, Cella DF, Webster K, Blendowski C, Kaplan E. Measuring fatigue and other anemia-related symptoms with the Functional Assessment of Cancer Therapy (FACT) measurement system. J Pain Symptom Manage. 1997;13(2):63-74.

36. Cormie P, Newton RU, Spry N, Joseph D, Taaffe DR, Galvao DA. Safety and efficacy of resistance exercise in prostate cancer patients with bone metastases. Prostate Cancer Prostatic Dis. 2013;16(4):328-335.

37. O'Neill RF, Haseen F, Murray LJ, O'Sullivan JM, Cantwell MM. A randomised controlled trial to evaluate the efficacy of a 6-month dietary and physical activity intervention for patients receiving androgen deprivation therapy for prostate cancer. $J$ Cancer Surviv. 2015;9(3):431-440.

38. Cormie P, Galvao DA, Spry N, et al. Can supervised exercise prevent treatment toxicity in patients with prostate cancer initiating androgen-deprivation therapy: a randomised controlled trial. BJU Int. 2015;115(2):256-266.

39. Hasenoehrl T, Keilani M, Sedghi Komanadj T, et al. The effects of resistance exercise on physical performance and health-related quality of life in prostate cancer patients: a systematic review. Support Care Cancer. 2015;23(8):2479-2497.

40. Keating NL, O'Malley AJ, Freedland SJ, Smith MR. Diabetes and cardiovascular disease during androgen deprivation therapy: observational study of veterans with prostate cancer. $J$ Natl Cancer Inst. 2010;102(1):39-46.

41. FDA drug safety communication: update to ongoing safety review of $\mathrm{GnRH}$ agonists and notification to manufacturers of $\mathrm{GnRH}$ agonists to add new safety information to labeling regarding increased risk of diabetes and certain cardiovascular diseases; 2010. Silver Spring (MD): US Food and Drug Administration. Available from: http://www.fda. gov/Drugs/DrugSafety/ucm229986.htm. Accessed April 29, 2016.

42. Efstathiou JA, Bae K, Shipley WU, et al. Cardiovascular mortality after androgen deprivation therapy for locally advanced prostate cancer: RTOG 85-31. J Clin Oncol. 2009;27(1):92-99.

43. Blair SN, Jackson AS. Physical fitness and activity as separate heart disease risk factors: a meta-analysis. Med Sci Sports Exerc. 2001;33(5):762-764.

44. Fagard RH. Exercise characteristics and the blood pressure response to dynamic physical training. Med Sci Sports Exerc. 2001;33(6 Suppl):S484-S492; discussion S493-S494.

45. Leon AS, Rice T, Mandel S, et al. Blood lipid response to 20 weeks of supervised exercise in a large biracial population: the HERITAGE Family Study. Metabolism. 2000;49(4):513-520.

46. Thompson PD, Buchner D, Pina IL, et al. Exercise and physical activity in the prevention and treatment of atherosclerotic cardiovascular disease: a statement from the Council on Clinical Cardiology (Subcommittee on Exercise, Rehabilitation, and Prevention) and the Council on Nutrition, Physical Activity, and Metabolism (Subcommittee on Physical Activity). Circulation. 2003;107(24):3109-3116.

47. Rafieian-Kopaei M, Setorki M, Doudi M, Baradaran A, Nasri H. Atherosclerosis: process, indicators, risk factors and new hopes. Int $J$ Prev Med. 2014;5(8):927-946.
48. Ridker PM. LDL cholesterol: controversies and future therapeutic directions. Lancet. 2014;384(9943):607-617.

49. Galvão DA, Spry NA, Taaffe DR, et al. Changes in muscle, fat and bone mass after 36 weeks of maximal androgen blockade for prostate cancer. BJU Int. 2008;102(1):44-47.

50. Greenspan SL, Coates P, Sereika SM, Nelson JB, Trump DL, Resnick NM. Bone loss after initiation of androgen deprivation therapy in patients with prostate cancer. JClin Endocrinol Metab. 2005;90(12):6410-6417.

51. Morote J, Morin JP, Orsola A, et al. Prevalence of osteoporosis during long-term androgen deprivation therapy in patients with prostate cancer. Urology. 2007;69(3):500-504.

52. Ebeling PR. Clinical practice. Osteoporosis in men. $N$ Engl $J$ Med. 2008;358(14):1474-1482.

53. Hamilton EJ, Ghasem-Zadeh A, Gianatti E, et al. Structural decay of bone microarchitecture in men with prostate cancer treated with androgen deprivation therapy. J Clin Endocrinol Metab. 2010;95(12): E456-E463.

54. De Laet C, Kanis JA, Oden A, et al. Body mass index as a predictor of fracture risk: a meta-analysis. Osteoporos Int. 2005;16(11):1330-1338.

55. Gonnelli S, Caffarelli C, Nuti R. Obesity and fracture risk. Clin Cases Miner Bone Metab. 2014;11(1):9-14.

56. Zhang P, Peterson M, Su GL, Wang SC. Visceral adiposity is negatively associated with bone density and muscle attenuation. Am J Clin Nutr. 2015;101(2):337-343

57. Kerr D, Morton A, Dick I, Prince R. Exercise effects on bone mass in postmenopausal women are site-specific and load-dependent. $J$ Bone Miner Res. 1996;11(2):218-225.

58. Maddalozzo GF, Snow CM. High intensity resistance training: effects on bone in older men and women. Calcif Tissue Int. 2000;66(6): 399-404.

59. Vincent KR, Braith RW. Resistance exercise and bone turnover in elderly men and women. Med Sci Sports Exerc. 2002;34(1):17-23.

60. Carlin BI, Andriole GL. The natural history, skeletal complications, and management of bone metastases in patients with prostate carcinoma. Cancer. 2000;88(12 Suppl):2989-2994.

61. Alibhai SM, Duong-Hua M, Cheung AM, et al. Fracture types and risk factors in men with prostate cancer on androgen deprivation therapy: a matched cohort study of 19,079 men. J Urol. 2010;184(3):918-923.

62. Bober SL, Varela VS. Sexuality in adult cancer survivors: challenges and intervention. J Clin Oncol. 2012;30(30):3712-3719.

63. Ng E, Woo HH, Turner S, Leong E, Jackson M, Spry N. The influence of testosterone suppression and recovery on sexual function in men with prostate cancer: observations from a prospective study in men undergoing intermittent androgen suppression. JUrol. 2012;187(6):2162-2166.

64. Resnick MJ, Koyama T, Fan KH, et al. Long-term functional outcomes after treatment for localized prostate cancer. $N$ Engl J Med. 2013;368(5):436-445.

65. Kratzik CW, Lackner JE, Mark I, et al. How much physical activity is needed to maintain erectile function? Results of the Androx Vienna Municipality Study. Eur Urol. 2009;55(2):509-516.

66. Cormie P, Newton RU, Taaffe DR, et al. Exercise maintains sexual activity in men undergoing androgen suppression for prostate cancer: a randomized controlled trial. Prostate Cancer Prostatic Dis. 2013;16(2): $170-175$.

67. Hamilton K, Chambers SK, Legg M, Oliffe JL, Cormie P. Sexuality and exercise in men undergoing androgen deprivation therapy for prostate cancer. Support Care Cancer. 2015;23(1):133-142.

68. Braga-Basaria M, Dobs AS, Muller DC, et al. Metabolic syndrome in men with prostate cancer undergoing long-term androgen-deprivation therapy. J Clin Oncol. 2006;24(24):3979-3983.

69. Alberti KG, Eckel RH, Grundy SM, et al. Harmonizing the metabolic syndrome: a joint interim statement of the International Diabetes Federation Task Force on Epidemiology and Prevention; National Heart, Lung, and Blood Institute; American Heart Association; World Heart Federation; International Atherosclerosis Society; and International Association for the Study of Obesity. Circulation. 2009;120(16):1640-1645. 
70. Nobes JP, Langley SE, Klopper T, Russell-Jones D, Laing RW. A prospective, randomized pilot study evaluating the effects of metformin and lifestyle intervention on patients with prostate cancer receiving androgen deprivation therapy. BJU Int. 2012;109(10):1495-1502.

71. Morote J, Gómez-Caamaño A, Alvarez-Ossorio JL, et al. The metabolic syndrome and its components in patients with prostate cancer on androgen deprivation therapy. J Urol. 2015;193(6):1963-1969.

72. Smith MR, Finkelstein JS, McGovern FJ, et al. Changes in body composition during androgen deprivation therapy for prostate cancer. $J$ Clin Endocrinol Metab. 2002;87(2):599-603.

73. Smith MR, Lee H, McGovern F, et al. Metabolic changes during gonadotropin-releasing hormone agonist therapy for prostate cancer: differences from the classic metabolic syndrome. Cancer. 2008;112(10):2188-2194.

74. Galvão DA, Spry N, Denham J, et al. A multicentre year-long randomised controlled trial of exercise training targeting physical functioning in men with prostate cancer previously treated with androgen suppression and radiation from TROG 03.04 RADAR. Eur Urol. 2014;65(5):856-864.

75. Newton RU, Taaffe DR, Spry N, et al. Can exercise ameliorate treatment toxicity during the initial phase of testosterone deprivation in prostate cancer patients? Is this more effective than delayed rehabilitation? BMC Cancer. 2012;12:432.

76. Brown JK, Byers T, Doyle C, et al. Nutrition and physical activity during and after cancer treatment: an American Cancer Society guide for informed choices. CA Cancer J Clin. 2003;53(5):268-291.

77. Schmitz KH, Courneya KS, Matthews C, et al. American College of Sports Medicine roundtable on exercise guidelines for cancer survivors. Med Sci Sports Exerc. 2010;42(7):1409-1426.

78. Bourke L, Sohanpal R, Nanton V, Crank H, Rosario DJ, Saxton JM. A qualitative study evaluating experiences of a lifestyle intervention in men with prostate cancer undergoing androgen suppression therapy. Trials. 2012;13:208.

79. Holzbeierlein JM, Castle E, Thrasher JB. Complications of androgen deprivation therapy: prevention and treatment. Oncology (Williston Park). 2004;18(3):303-309; discussion 310, 315, 319-321.

80. Moyad MA. Promoting general health during androgen deprivation therapy (ADT): a rapid 10-step review for your patients. Urol Oncol. 2005;23(1):56-64.

81. Spriet LL. Exercise and sport performance with low doses of caffeine. Sports Med. 2014;44(Suppl 2):S175-S184.

82. Cornish RS, Bolam KA, Skinner TL. Effect of caffeine on exercise capacity and function in prostate cancer survivors. Med Sci Sports Exerc. 2015;47(3):468-475.

83. Tang BM, Eslick GD, Nowson C, Smith C, Bensoussan A. Use of calcium or calcium in combination with vitamin $\mathrm{D}$ supplementation to prevent fractures and bone loss in people aged 50 years and older: a meta-analysis. Lancet. 2007;370(9588):657-666.

84. Mottet N, Bastian PJ, Bellmunt J, et al. Guidelines on Prostate Cancer. 2014. European Association of Urology. Available from: https://uroweb org/.../1607-Prostate-Cancer_LRV3.pdf. Accessed June 28, 2016.

85. Institute of Medicine (US) Committee to Review Dietary Reference Intakes for Vitamin D and Calcium; Ross AC, Taylor CL, Yaktine AL, Del Valle HB, editors. Dietary Reference Intakes for Calcium and Vitamin D. Washington (DC): The National Academies Press; 2011.
86. Cosman F, de Beur SJ, LeBoff MS, et al. Clinician's Guide to Prevention and Treatment of Osteoporosis. Osteoporos Int. 2014;25(10): 2359-2381.

87. Datta M, Schwartz GG. Calcium and vitamin D supplementation during androgen deprivation therapy for prostate cancer: a critical review. Oncologist. 2012;17(9):1171-1179.

88. Alibhai SM, Mohamedali HZ, Gulamhusein H, et al. Changes in bone mineral density in men starting androgen deprivation therapy and the protective role of vitamin D. Osteoporos Int. 2013;24(10):2571-2579.

89. Klein S, Burke LE, Bray GA, et al. Clinical implications of obesity with specific focus on cardiovascular disease: a statement for professionals from the American Heart Association Council on Nutrition, Physical Activity, and Metabolism: endorsed by the American College of Cardiology Foundation. Circulation. 2004;110(18):2952-2967.

90. Galvão DA, Taaffe DR, Spry N, Joseph D, Newton RU. Acute versus chronic exposure to androgen suppression for prostate cancer: impact on the exercise response. J Urol. 2011;186(4):1291-1297.

91. Wing RR. Physical activity in the treatment of the adulthood overweight and obesity: current evidence and research issues. Med Sci Sports Exerc. 1999;31(11 Suppl):S547-S552.

92. Cermak NM, Res PT, de Groot LC, Saris WH, van Loon LJ. Protein supplementation augments the adaptive response of skeletal muscle to resistance-type exercise training: a meta-analysis. Am J Clin Nutr. 2012;96(6):1454-1464.

93. Miller PE, Alexander DD, Perez V. Effects of whey protein and resistance exercise on body composition: a meta-analysis of randomized controlled trials. J Am Coll Nutr. 2014;33(2):163-175.

94. Barton DL, Liu H, Dakhil SR, et al. Wisconsin Ginseng (Panax quinquefolius) to improve cancer-related fatigue: a randomized, doubleblind trial, N07C2. J Natl Cancer Inst. 2013;105(16):1230-1238.

95. US FDA News Release P04-89. FDA Announces Qualified Health Claims for Omega-3 Fatty Acids. 2004. Silver Spring (MD): US Food and Drug Administration. Available from: http://www.fda.gov/ SiteIndex/ucm108351.htm. Accessed March 3, 2016.

96. Kris-Etherton PM, Harris WS, Appel LJ, for the AHA Nutrition Committee. Omega-3 fatty acids and cardiovascular disease: new recommendations from the American Heart Association. Arterioscler Thromb Vasc Biol. 2003;23(2):151-152.

97. Oikawa S, Yokoyama M, Origasa H, et al. Suppressive effect of EPA on the incidence of coronary events in hypercholesterolemia with impaired glucose metabolism: sub-analysis of the Japan EPA Lipid Intervention Study (JELIS). Atherosclerosis. 2009;206(2): 535-539.

98. Yokoyama M, Origasa H, Matsuzaki M, et al. Effects of eicosapentaenoic acid on major coronary events in hypercholesterolaemic patients (JELIS): a randomised open-label, blinded endpoint analysis. Lancet. 2007;369(9567):1090-1098.

99. Grossmann M, Zajac JD. Hematological changes during androgen deprivation therapy. Asian J Androl. 2012;14(2):187-192.

100. Bailey CA, Brooke-Wavell K. Optimum frequency of exercise for bone health: randomised controlled trial of a high-impact unilateral intervention. Bone. 2010;46(4):1043-1049.

101. Frisk J. Managing hot flushes in men after prostate cancer - a systematic review. Maturitas. 2010;65(1):15-22.
Research and Reports in Urology

\section{Publish your work in this journal}

Research and Reports in Urology is an international, peer-reviewed, open access journal publishing original research, reports, editorials, reviews and commentaries on all aspects of adult and pediatric urology in the clinic and laboratory including the following topics: Pathology, pathophysiology of urological disease; Investigation and treatment of urological disease; Pharmacology of drugs used for the treatment of urological disease. The manuscript management system is completely online and includes a very quick and fair peer-review system, which is all easy to use. Visit http://www.dovepress.com/testimonials.php to read real quotes from published authors. 